\title{
Renal Urinary Enzymes in Rheumatoid Arthritis Dejan Spasovski*
}

University Clinic of Rheumatology, Clinical Center “ Mother Therese”, Skopje, Faculty of medicine, Republic of North Macedonia.

*Corresponding Author: Dejan Spasovski, University Clinic for Rheumatology, faculty of medicine, University Clinical Center "Mother Therese", Skopje, Republic of North Macedonia.

\section{Abstract}

Introduction: As an indicator of proximal tubular damage is used urinary excretion $N$-acetyl- $\beta$ - $D$ glucosaminidase (NAG), while Microalbuminuria is used as a tracer for glomerular damage

Aim: The aim of the study is to determined effect of toxicity of these medicals by affecting the enzymuria that correlate with the damage of the epithelium of proximal tubular. To quantifice effects of the treatment with Etoricoxib and Diclofenac on renal proximal tubular in patients with Rheumatoid Arthritis (RA).

Methods: NAG is detected with colorimetric method. Microalbuminuria is detected with method odimmunoturbidimetric. Tests were performed on 70 participants (35 RA treated with Etoricoxib, 35 RA patients with Diclofenac) in four time intervals in the eight weeks.

Results: Correlation between NAG and microalbuminuria ( $r=0.21)$ in the group of patients treated with Etoricoxib is moderate, while correlation $(r=0.28)$ in the group with Diclofenac was significant. NAG enzymuria, in volume, number of participants in whom it was registered and at the time of its occurrence was much faster during the use of Diclofenac in relation to Etoricoxib.

Conclussion: Diclofenac is a potent NAG-inductor and gives a larger tubular enzymuria in comparison with Etoricoxib.

Keywords: $N$-acetyl- $\beta$-D-glucosaminidase, microalbuminuria, rheumatoid arthritis, Etoricoxib, Diclofenac.

\section{INTRODUCTION}

Microalbuminuria is used as a marker for glomerular damage and urinary excretion of N-Acetyl- $\beta$-Dglucosaminidase (NAG) as an indicator of proximal tubular damage. These tests indicate that, there is no specific indicator, tracer, marker, which detects nephrotoxicity that occurs in the course of the therapy.

Many uses of certain groups of drugs for therapeutic purposes (NSAIDs, drugs that modify disease activity (DMRADs and immunosuppressive cytotoxic drugs), may have a specific nephrotoxic effect. The given dose is often not suitable for the patient's condition, it can cause side effects, ie it can lead to reduction of the kidney function, as a result of accumulation in the kidneys' cells. This is usually found in long-term therapy as in Rheumatoid arthritis.

\section{URINARY ENZYMES TO ASSESS NEPHROTOXICITY}

Albumin in urine, (Microalbuminuria). Albumin (molecular weight of $66 \mathrm{KDa}$ ) is the most important protein in plasma, as well in urine. Approximately 30\% of the protein in the urine belongs to it and presents a good indicator for assessing the change in glomerular permeability. Urinary albumin excretion has a high individual variability and depends on physical activity or food variations $(1,2)$. .

From all the urinary enzymes the most examined is U-NAG (urinary). This enzyme from the hydrolase class is abundantly present in lysosomes in proximal tubular cells. In human tissue and biological liquids there are two main enzyme forms: A (Acid) and B (Basic) (3-5). The percentage of isoform A (U-NAG-A) is the highest in normal urine $(3,4)$. Therefore, its excretion is related to the exfolliative turnover and is known as a functional enzymuria (5-14). 


\section{Materials AND METhodS}

Patients diagnosis is mades from on the diagnostic criteria for classification of Rheumatoid arthritis from American Association for Rheumatism (ARA) (15). Criteria from 1 to 4 were present for at least 6 months. The study included 35 patients with RA (women 20, males 15) treated with Etoricozhib, as well as 35 patients with RA (women 22, males 13) treated with Diclofenac. The ages, means was 50.43 years $( \pm 6.42)$ (38-65 years) in the treated group with Etoricohib, while 50.13 years $( \pm 8.36)$ (39-65 years) in the group treated with Diclofenac. None of the patients used previously NSAID. The others did not use other drugs before taking the test, especially gold salts or antibiotics or diuretics. The samples were collected in period of 8 weeks.

\section{INCLUDING CRITERIA}

Patients with RA was included in this research, in the age 18-65 years. All patients were not previously treated with NSAIDs or DMARDs.

\section{EXCLUDing CRITERIA}

1. Patients with a history of gonorrhea, mild to moderate hepatic, renal, hematologic, cardiovascular, neurological diseases, nausea, vomiting, autoimmune disease.

2. Patients with, diabetes mellitus, neoplasms mixed connective tissue disease

3. Patients with urinary tract arthritis, vasculitis.

4. Patients with a history of blood transfusion, and excessive body weight. febrile condition SLE

5. Excluded from the study was patients who receive baseline therapy for RA

6. Patient with a history of glycemia or increased levels of product degradation in the 0 -th range: serum creatine and urine, serum urea, hypertension, arterial hypertension, and hematological and enzyme status. urinary tract infections

7. Patients previously treated with salicylates, antibiotics, gold salts, or diuretics, acute infections

All participants voluntarily took part in this study, so that the criteria to do it are met.

Clinical Assessment with Disease Activity Score (DAS28) Index

Clinical assessment was made by sub specialist in the given area Disease Activity Score (DAS 28) index (1618) Score below 3.2 qualifies the disease as low active.
DAS 28 indexes range from 0 to 10 .

\section{Laboratory Assessment}

For clinical assessment of disease, it is necessary to consider the following laboratory variables: aspartate aminotransferase (AST), urea / serum, creatinine / serum. Erytrocite sedimentation rate (ESR), C-reactive protein (CRP), ACPA antibodies, alanine aminotransferase (ALT), Complete blood count (CBC) and differential, creatine kinase (CK), Rheumatoid factor (RF), lactate dehydrogenase (LDH), acute phase reactants, alkaline phosphatase (AF).

Determination of Microalbuminuria by Immunoturbidimetric Method (Randox Laboratories Limited)

Reference values: Microalbuminuria 2.0-20.0 mg / L Determination of N-Acetyl-A-D-Glucosaminidase (Nag) Activity: Colorimetric Method (Roche)

\section{Principle}

3-Cresolsulfonphthaleinyl-N-Acetyl- $\alpha$-D-glucosaminide, as sodium salt, is hydrolyzed by NAG to release 3-cresolsulfonphthalein, sodium salt (3-cresol purple) which iphotometrically is measured at $5 \mathrm{~nm}$ (Roche mancheim kits). The urine that is examined previously is centrifuged and supernatants separated.

Reference values: NAG in urine 0.27-1.18 U / mmol creatine

\section{STATistical Analysis}

Two arithmetic means is testing of the differences between i.e. the corresponding proportions, the Student t-test is used, when comparing the mean values of the given number of parameters between two groups, such as Wilcoxon- matched test for independent samples. predictivity and sensitivity for negative and negative tests of the examined markers is determined with tests for sensitivity and specificity. Statistically significant is the $P$ value of between 0.05 and 0.1 is considered. Statistical package Statistica 7.0 is used for data preceding

\section{RESULTS}

Between NAG and microalbuminuria, Pearson's analysis of $\mathrm{c} 2$ test showed that there was correlation, which was moderate $(r=0.21)$ in the four samples tested during the period of 8 weeks in patient's group treated only with Etoricoxib, while there was 
statistically significant correlation $(r=0.28)$ between increase in NAG and microalbuminuria values in the four samples in the period of 8 weeks in the group Diklofenak. (Fig No. 1).

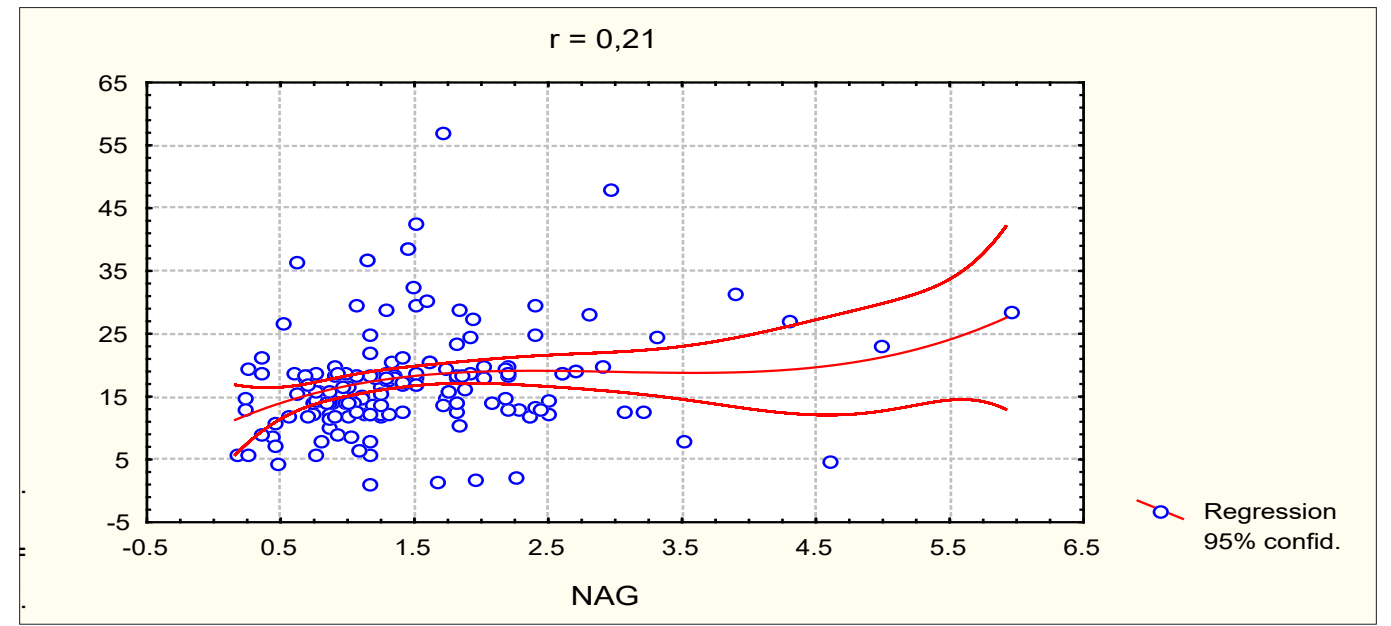

Fig1. Pearson coefficient of correlation ( $r$ ) between NAG and microalbuminuria values in the groups treated with Etoricoxib. There is correlation between NAG and microalbuminuria $(r=0.21)$.

There is significance of the differences in the two groups in the group of treated with Etoricoxib, where the value mean of the microalbuminuria was $(0.46 \pm 0.37)$, while in the patients group treated with Diclofenac was $(0.56 \pm 0.41)$. This explains why Etoricoxib gives almost identical value to microalbuminuria in relation to Diclofenac.

Group of patients treated with Etoricoxib in relation to the distribution of patients according to the values of NAG in the four groups, it was concluded that the values of NAG were registered in 4 patients in the 3rd week, when the mean value of NAG urinary induction was highest $(1.12 \pm 0.13)$.

It was concluded that NAG values were registered in 6 patients in the $3 \mathrm{rd}$ week, when the mean value of NAG urinary induction was highest $(1.41 \pm 0.31)$. Analyzing patient's distributions according to NAG values in the four probes in the group of patients treated only with Diclofenac.

\section{Discussion}

Approaches for the assessment of nephrotoxicity of drugs are possible only with drugs or medications that have a dominant proximal tubular excretion, such as Methotrexate, Etoricoxib, Diclofenac, Acetaminophen and gold salts. This approach for the assessment of nephrotoxicity of drugs is not possible with other medications or drugs from the baseline which are used in the treatment of RA, such as resorhin, sulfazalazine and leflunomide, due to predominantly hepatic excretion. For these preparations there are no literarature data on the occurrence of proximal tubular dysfunction. Methotrexate in the low-dose regimen is the most commonly used drug from the DMARDs group, while from the NSAIL group the most commonly used drug is Diclofenum (Diklofenak R ), as well as Etoricoxib (Arcoxia R).

In the non-treated RA primarily is damaged tubular and to a very small extent the glomerular apparatus.(19). Significant increase in the activity is due to changes in cellular synthesis and not always the enzymuria may result in lytic or necrotic processes. Etoricohib does not cause significant damage to the renal proximal tubules in the most of monitored patients. The nephrotoxicity during the use of Diclofenac is greater in relation to Etoricohib. Diclofenac is discretely more potent NAG inductor in relation to Etoricohib. These observations correspond with other authors $(20,21)$.

Early detection of increased NAG enzymuria or occurrence of microalbuminuria before exposure to drugs may be used for prediction of possible toxicity associated with renal impairment.

There was not any change in clinical findings of renal function in relation to degradation products of nitrogen metabolism (serum creatine, urea / serum, GFR) during the follow-up. 


\section{ConCLUSION}

Enzymura detected with urinary NAG, together with degradation product with urinary creatinine excretion may be considered as a complementary diagnostic tool.

The results obtained in some studies confirmed the safety of Etoricoxib and Diclofenac in the treatment of RA.

\section{REFERENCES}

[1] Microalbuminuria: an early marker of renal involvement in diabetes. Morgensen CE,Chachati A,Christensen CK,Close CF,Deckert T,Hommel E,Kastrup J,Lefebvre P,Mathiesen ER,FeldtRasmussen B,et al.Uremia Invest ( 1986) 9:85-95.

[2] Microalbuminuria in diabetes mellitus: review and recommendations for the measurment of albumin in urine, DJ F Rowe A Dawnay G F Watts, Ann Clin Biochem 1990;27:297-312.

[3] Lockwood TD, Bosmann HB. The use of N-acetylglucosaminidase in human renal toxicology. 1. Partial biochemical Characterization and excretion in human and release from the isolated rat kidney. Toxicol Appl Pharmacol 1979;49:323-36.

[4] Gibey R, Dupond JL, Henry JC. Urinary $N$-acetylD-glucosaminidase isoenzyme profile: a tool for evaluating nephrotoxicity of aminoglycosides and cephalosporins. Clin Chim Acta 1984;137:1-11.

[5] Paigen K, Peterson J.Coordinacy of lysosomal enzyme excretion in human urine.J Clin Invest 1978; 61:751-62

[6] Bourbouze R, Bernard M, Baumann FCh, PerezGonzales N, Martin-Barientos J, Cabezas JA. Subcellular distribution of the $N$-acetyl-b-Dglucosaminidase isoenzymes from rabbit kidney cortex. Cell Mol Biol 1984;32:67-74.

[7] Burton CJ, Walls J (1994) Proximal tubular cell, proteinuria and tubulo-interstitial scarring. Nephron 68:287-293.

[8] Chiu JSP.Models used to asses renal function. Drug Devel Res 1994;32:247-55.

[9] Price RG. Measurement of $N$-acetyl-bglucosaminidase and its isoenzymes in urine, methods and clinical applications. Eur J Clin Chem Clin Biochem 1992;30:693-705.
[10] Price RG. The role of NAG ( N-acetyl-Dglucosaminidase) in the diagnosis of kidney disease including the monitoring of nephrotoxicity. Clin Nephrol 1992;38:14-19.

[11] Tucker SM,Pierce RJ,Price RG.Characterization of human $\mathrm{N}$-acetyl-D-glicosaminidase isoenzymes as an indicator of tissue damage in disease.Clin Chim Acta 1980;102:29-40.

[12] van Gestel AM, Prevoo ML, van 't Hof MA, van Rijswijk MH. Development and validation of the European league against rheumatism response criteria for rheumatoid arthritis. Comparison with the preliminary American college of rheumatology and the world health organization/ international league against rheumatism criteria. Arthritis Rheum 1996; 39: 34-40.

[13] Prevoo ML, van 't Hof MA, Kuper HH, van Leeuwen MA. Modified disease activity scores that include twenty-eight-joint counts. Development and validation in a prospective longitudinal study of patients with rheumatoid arthritis. Arthritis Rheum 1995; 38: 44-8.

[14] Balsa A, Carmona L, Gonzalez-Alvaro I, Belmonte MA. Value of DAS-28 and DAS 28-3 as compared to ACR-defined remission in rheumatoid arthritis. J Rheumatol 2004; 31: 40-6.

[15] Prevoo ML, van Gestel AM, van T Hof MA, van Rijswijk MH. Remission in a prospective study of patients with rheumatoid arthritis. American rheumatism association preliminary remission criteria in relation to the disease activity score. Br J Rheumatol 1996; 35: 1101-5.

[16] Spasovski D, Gruev T, Marina N, et al. The diagnostic value of $\mathrm{N}$-acetyl-b-D-glucosaminidase and microalbumin concentrations in rheumatoid arthritis. JMB 2007; 26: 300-8.

[17] Boers M, Dijkmans BA, Breedveld FC, Camps JA, Chang PC, van Brummelen P,et al. Subclinical renal dysfunction in rheumatoid arthritis. Arthritis Rheum. 1990; 33: 95-101.

[18] Knudsen LS, Klarlund M, Skjodt H, Jensen T, Ostergaard $\mathrm{M}$, Jensen KE,et all. Biomarkers of inflammation in patients with unclassified polyarthritis and early rheumatoid arthritis. Relationship to disease activity and radiographic outcome. J Rheumatol 2008; 35:1277-87. 
[19] Koseki Y, Terai C, Moriguchi M, Uesato M, Kamatani N. A prospective study of renal disease in patients with early rheumatoid arthritis. Ann Rheum Dis 2001; 60: 327-31.

[20] Marchewka Z, Przewłocki M, Lepka M, Długosz A, Kochman K. Selected biochemical parameters of urine in the evaluation of paracetamol nephrotoxicity. Przegl Lek 2006; 63: 1299-303.

[21] da Silva Melo DA, Saciura VC, Poloni JA, Oliveira CS, Filho JC, Padilha RZ,et al. Evaluation of renal enzymuria and cellular excretion as an marker of acute nephrotoxicity due to an overdose of paracetamol. Clin Chim Acta 2006;373: 88-9.

Citation: Dejan Spasovski. Renal Urinary Enzymes in Rheumatoid Arthritis. Archives of Emergency Medicine and Intensive Care. 2020; 2(2): 25-29.

Copyright: (C) 2020 Dejan Spasovski. This is an open access article distributed under the Creative Commons Attribution License, which permits unrestricted use, distribution, and reproduction in any medium, provided the original work is properly cited. 